\title{
Solvent Effect on Morphology and Optical Properties of Poly(3-hexylthiophene):TIPS-Pentacene Blends
}

\author{
MAÍZA SILVA OZÓRIO, ${ }^{1,3}$ SABRINA ALESSIO CAMACHO, ${ }^{1}$ \\ NEUSMAR JUNIOR ARTICO CORDEIRO ${ }^{2}$ JOSÉ LEONIL DUARTE, ${ }^{2}$ \\ and NERI ALVES ${ }^{1}$
}

1.-School of Technology and Applied Sciences, São Paulo State University (UNESP), Campus Presidente Prudente, São Paulo, SP, Brazil. 2.-Department of Physics, Londrina State University (UEL), Londrina, PR, Brazil. 3.—e-mail: ozoriounesp@gmail.com

Optical, electrical, and morphological properties of poly(3-hexylthiophene):6,13-bis(triisopropylsilylethynyl) (TIPS)-pentacene (P3HT:TP) blend films, in the proportion of 1:1 (w/w), have been investigated using chloroform, toluene, or trichlorobenzene as solvent. The main morphological feature was formation of aggregates that tended to segregate vertically, exhibiting characteristics that were strongly influenced by the type of solvent applied. The phase segregation of TP observed for the P3HT:TP blend film obtained using chloroform, the most volatile of the investigated solvents, can be explained based on the Marangoni effect and the Flory-Huggins model. The TP molecules induce better organization of $\mathrm{P} 3 \mathrm{HT}$, as evidenced by the ultravioletvisible (UV-Vis) absorption spectra. Photoluminescence (PL) measurements revealed quenching and an increase in the lifetime of the carriers. The PL measurements also showed that the exciton dissociation was dependent on the characteristics of the surface on which the film was deposited. P3HT:TP blend film prepared using trichlorobenzene showed the best morphology with moderate phase segregation and better P3HT ordering. The output current from organic field-effect transistors (OFETs) with blend film prepared using trichlorobenzene was three times $(3 \times)$ larger than when using the other solvents, with carrier mobility of $5.0 \times 10^{-3} \mathrm{~cm}^{2} \mathrm{~V}^{-1} \mathrm{~s}^{-1}$.

Key words: Semiconductor blend, TIPS-pentacene, vertical segregation, morphology, optical properties

\section{INTRODUCTION}

Conjugated polymers, oligomers, or small molecules are widely used as active layers in devices such as organic field-effect transistors (OFETs) and solar cells. ${ }^{1-4}$ One of the most extensively studied materials among organic semiconductors (OSCs) is pentacene, due to its high field-effect mobility and environmental stability, having the highest mobility of charge carriers. ${ }^{5-7}$ However, as its solubility is very poor, it is not suitable for use in printed electronics. Recently, it was shown that solution-

(Received May 22, 2017; accepted November 6, 2017; published online November 20, 2017) processable small-molecule semiconductors, such as 6,13-bis(triisopropylsilylethynyl) pentacene (TIPSpentacene) and 2,8-difluoro-5,11-bis(triethylsilylethynyl) anthradithiophene (diF-TESADT), exhibit mobility values exceeding $1 \mathrm{~cm}^{2} \mathrm{~V}^{-1} \mathrm{~s}^{-1}$ (i.e., comparable to, or higher than, that of a-Si:H, or vacuum-deposited organic materials). ${ }^{8,9}$ Although such high mobility values are compatible with printing techniques, use of these small-molecule semiconductors has been hindered by significant device-to-device performance variations, resulting from the difficulty of controlling the crystalline growth and morphology. ${ }^{10-13}$

High mobility values can be obtained by integration of small molecules within polymeric matrices. 
However, it is important to control the crystallization and vertical segregation of small molecules to produce devices with good performance. ${ }^{14}$ The type of molecule, the molecular weight $\left(M_{\mathrm{w}}\right)$ of the polymer matrix, the rate of solvent evaporation, the rates of crystallization of each component, the surface energy of the substrate, and other characteristics are factors that can influence the vertical segregation. ${ }^{15-19}$

Several approaches based on deposition methods are used in the manufacture of printed circuits, ${ }^{20,21}$ such as blade coating, inkjet printing, and spray coating, to process organic semiconductor thin films. However, spin coating, a solution-based processing method, is still one of the most widely used laboratory-scale methods for studying materials as well as device optimization. ${ }^{22}$ Uniform, thin, smooth, and continuous films can be achieved by dropping the solution on the substrate and subsequently spreading and drying it under rotation at high speed. TIPS-pentacene (TP) is a good example of a material for which the spin-coating parameters are of crucial importance for the morphology of its films. Chou et al. ${ }^{22}$ reported a study into the influence of solvent, rotation speed, temperature, and other parameters used in film deposition by spin coating, for instance, showing that the mobility changes from $0.28 \mathrm{~cm}^{2} \mathrm{~V}^{-1} \mathrm{~s}^{-1}$ to $0.021 \mathrm{~cm}^{2} \mathrm{~V}^{-1} \mathrm{~s}^{-1}$ when the speed rotation is increased from $300 \mathrm{rpm}$ to $1000 \mathrm{rpm}$.

This paper addresses the study of poly(3-hexylthiophene):TIPS-pentacene (P3HT:TP) blends in proportion of 1:1 (w/w), aiming to obtain film with good morphology for use as an active layer in organic devices. The principal focus is the solvent effect on the morphology and its influence on the optical properties. The results show that it is possible to design the morphology according to the desired applications. It is possible to prepare film in which the TP molecules segregate vertically to form aggregates that percolate at the superior surface, or in such a way that the TP molecules remain mostly distributed homogeneously in bulk. Also, the results show that, when TP is added to P3HT, quenching of the photoluminescence occurs, depending on the solvent as well as the substrate, accompanied by increases of the charge carrier lifetime and field-effect mobility.

\section{EXPERIMENTAL PROCEDURES}

As the morphology of the blends depends strongly on the substrate, this work on P3HT:TP blend films was realized using the architecture shown in Fig. 1, were there are three surfaces: glass, aluminum, and aluminum oxide. This approach is important for evaluating its performance from the viewpoint of transistor applications, in which the blend will be deposited onto a dielectric.

An aluminum layer with thickness of $200 \mathrm{~nm}$ was deposited on a glass substrate by thermal evaporation at high vacuum $\left(\sim 10^{-7} \mathrm{kPa}\right)$. The aluminum film was anodized at constant current to obtain aluminum oxide $\left(\mathrm{Al}_{2} \mathrm{O}_{3}\right)$ film with thickness of $60 \mathrm{~nm}$. The $\mathrm{Al}_{2} \mathrm{O}_{3}$ surface was treated using hexamethyldisilazane (HMDS) by immersion in solution for $3 \mathrm{~min}$, then washed in ketone and dried in nitrogen flow.

P3HT and TP, purchased from Sigma Aldrich ${ }^{\circledR}$, mixed in proportion of $1: 1(\mathrm{w}: \mathrm{w})$, were dissolved in chloroform, toluene, or trichlorobenzene, whose boiling points are $60^{\circ} \mathrm{C}, 110^{\circ} \mathrm{C}$, and $200^{\circ} \mathrm{C}$, respectively. The solution was filtered using a Millipore $0.45-\mu \mathrm{m}$ filter, then deposited on the $\mathrm{Al}_{2} \mathrm{O}_{3}$ by spin coating at $1000 \mathrm{rpm}$ for $60 \mathrm{~s}$ in a glovebox, producing films with thickness of $\sim 100 \mathrm{~nm}$. The P3HT:TP films were annealed at $100^{\circ} \mathrm{C}$ for $2 \mathrm{~h}$ in vacuum, to remove solvent residues. The morphology of the P3HT:TP blends were characterized by scanning electron microscopy (SEM) and optical analysis, such as ultraviolet-visible (UV-Vis) spectroscopy and photoluminescence (PL). Transistors were prepared to evaluate the field-effect mobility of the blend films. These devices were obtained by evaporating $\mathrm{Au}$ source and drain electrodes onto the P3HT:TP films in high vacuum $\left(\sim 10^{-7} \mathrm{kPa}\right)$. The length and width of the channel was $90 \mu \mathrm{m}$ and $3 \mathrm{~mm}$, respectively. The transistors were characterized based on their output and transfer curves using an SCS 4200 semiconductor characterization system.

\section{RESULTS AND DISCUSSION}

Figure 2 shows SEM images of the P3HT:TP blend films prepared using chloroform, where TP aggregates can be seen in the upper surface due to phase difference. This occurs because of the high volatility of the solvent (boiling point $\sim 60^{\circ} \mathrm{C}$ ), saturating the system very quickly while the spinner is rotating; this, associated with the high crystallization speed of TP, results in phase separation. Figure 3 illustrates the steps in film formation by spin-coating deposition, in which the mechanism responsible is described based on the Flory-Huggins model. $^{23}$ An important parameter in the FloryHuggins model is the energy variation when component $\mathrm{A}$ is removed from a place and substituted by component B. Step 1 in Fig. 3 illustrates that the high speed of the spinner rotation (1000 rpm) discards excess material, leaving highly saturated solution on the glass. Solvent evaporation increases the concentration of the solute and the viscosity of the solution, so the behavior of the phase segregation depends on the solvent type. The film formation is dominated by two interaction factors: solventsolute and solute-solute. ${ }^{24}$ In the first process, evaporation of the solvent at the top increases the solute concentration; as a consequence, there is an accumulation of the most soluble component at the upper interface, i.e., vertical segregation, as shown in step 2 of Fig. 3. Then, as the two components 


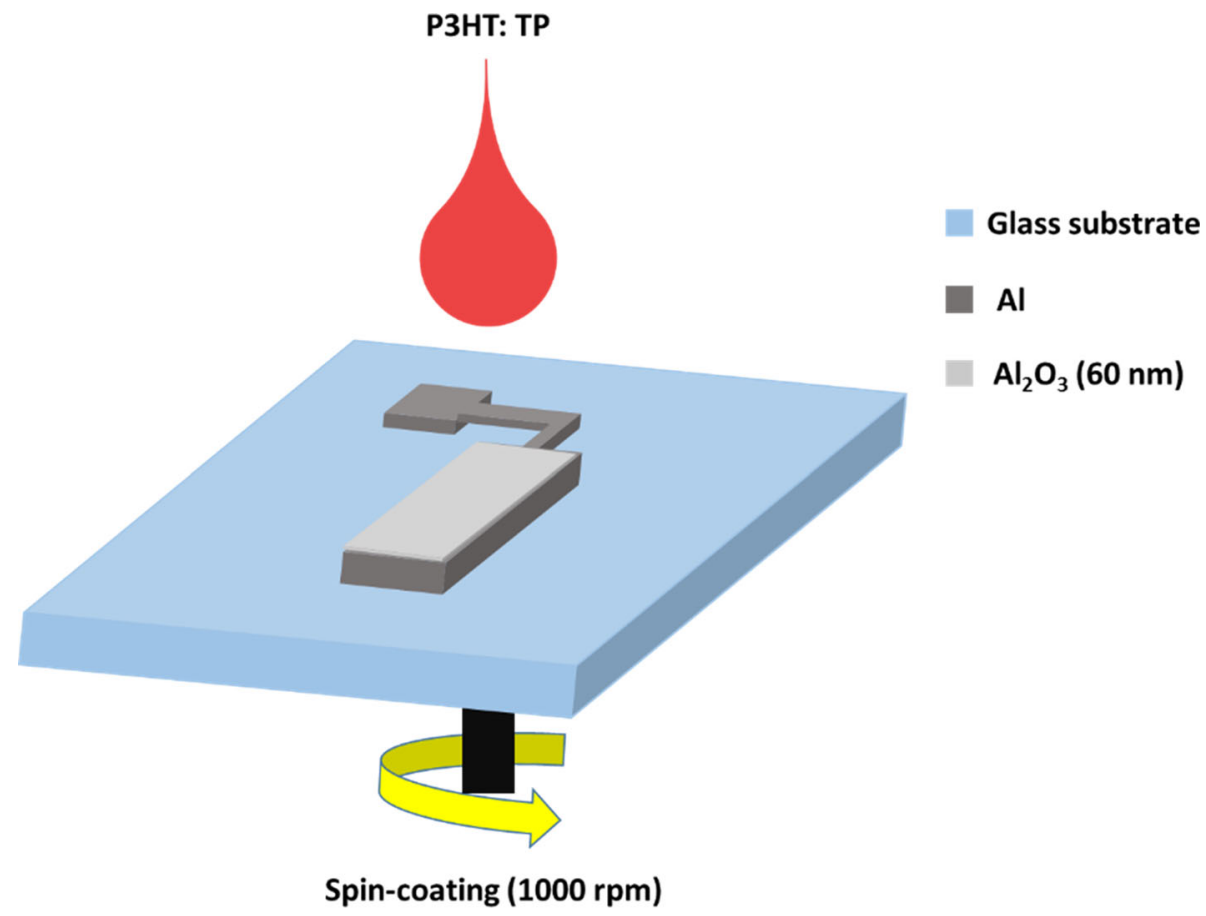

Fig. 1. Schematic of deposition of P3HT:TP blend film by spin coating on a glass substrate with $\mathrm{Al}$ layer and $\mathrm{Al}_{2} \mathrm{O}_{3}$.
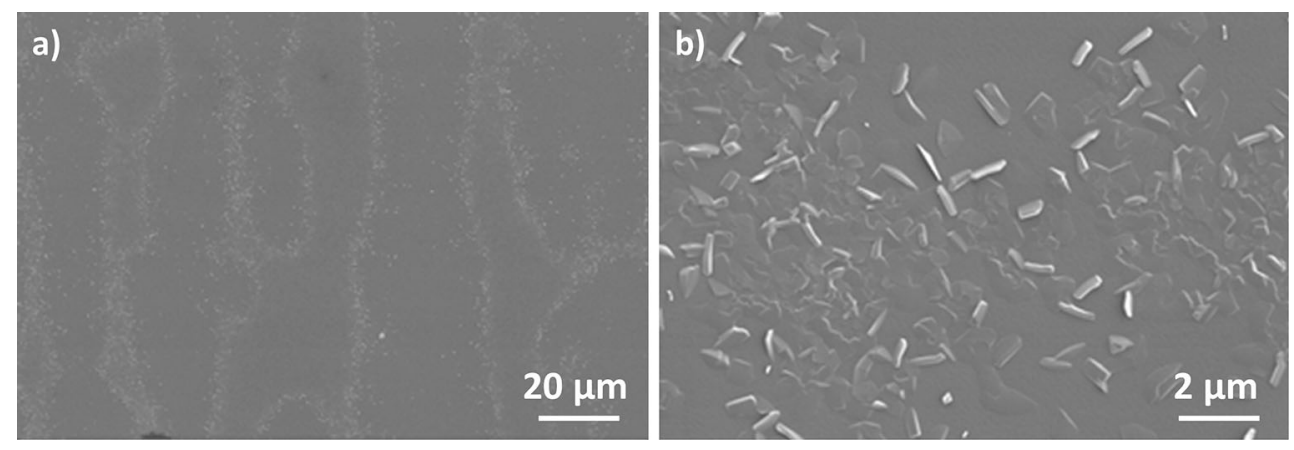

Fig. 2. SEM images of P3HT:TP blend films prepared with chloroform at magnification of (a) $\times 1000$ and (b) $\times 10,000$. The films show "stripes" or "stretch marks" due to the Marangoni effect.

solidify, the structure of the film is affected by crystallization, with the first component to solidify being expelled to the surface. In crystalline-crystalline systems, the phase segregation is induced by the first crystallizing component, ${ }^{23,25}$ as shown in step 3 of Fig. 3.

Films prepared using chloroform exhibited "stripes" or "stretch marks" due to the Marangoni effect (see the optical image in Fig. 3), which was not observed when using other solvents. Changes in surface tension due to variation in temperature, concentration gradient, and solvent type can produce the Marangoni effect. ${ }^{17,26}$ Several experimental studies have confirmed the influence of this effect on films deposited by spin coating, where highly volatile solvents have lower surface tension than the solute. ${ }^{27-29}$ The high volatility of the solvents and differences in surface tension of the solution associated with the spinner rotation do not allow sufficient time for good film organization, resulting in high roughness and structural defects. For better film organization, it is necessary to control the rate of solvent evaporation and spinner rotation. Another important factor is to know the properties of the surface of the substrate, in particular its roughness and wettability.

The morphology of P3HT:TP blend film prepared using toluene is shown in Fig. 4. The main difference observed between the blend prepared with toluene (Fig. 4b) and chloroform (Fig. 2b) lies in the ordering of the crystallites. The blend prepared using trichlorobenzene was more homogeneous and the segregation less intense, as observed in the SEM image in Fig. 5. There are no crystalline aggregates as seen for the other solvents. This occurs due to the low-volatility solvent, which makes the evaporation 


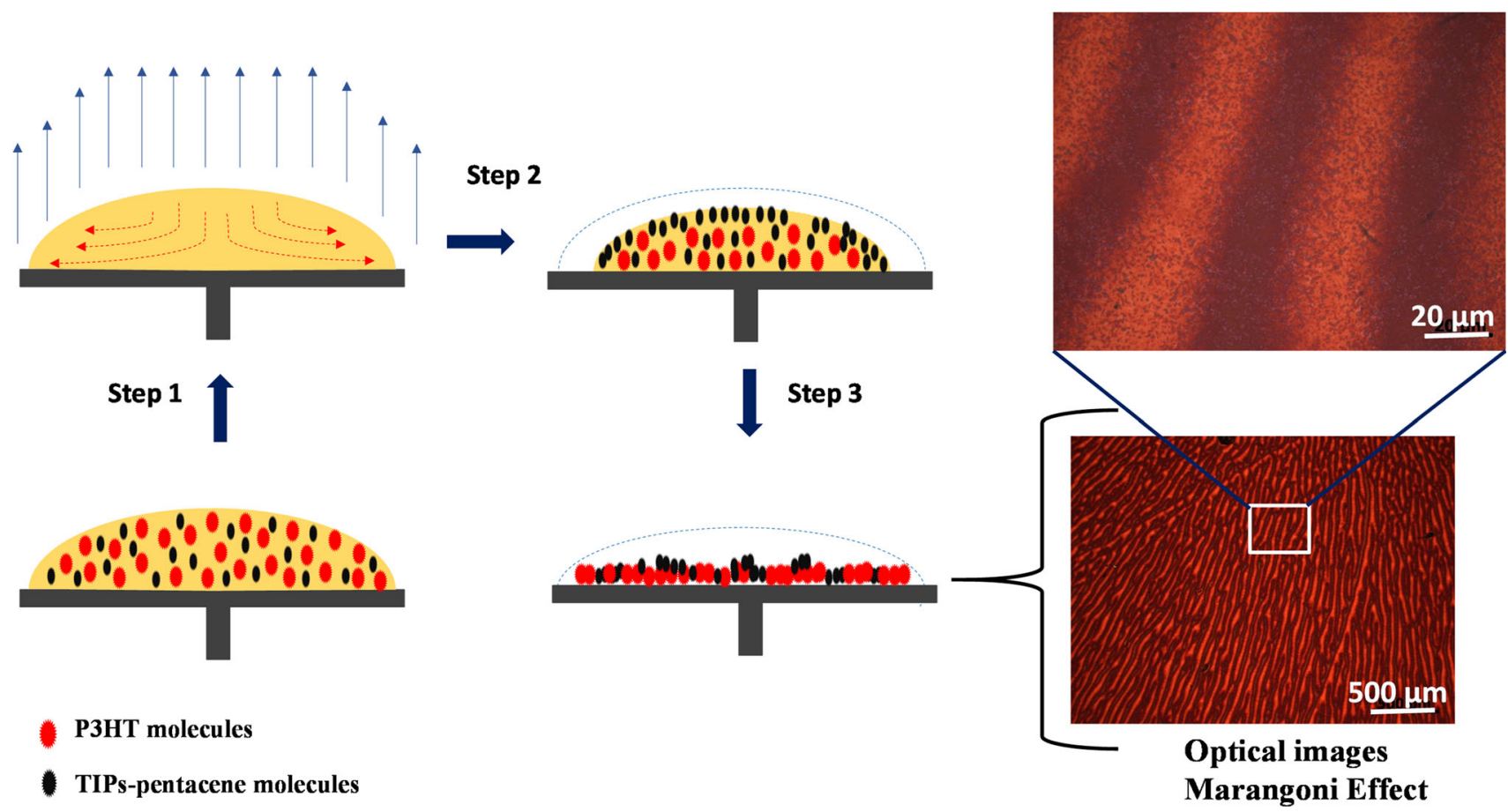

Fig. 3. Schematic of film-forming process of P3HT:TP blend prepared using chloroform. Step 1 illustrates the interaction between solventsolute, step 2 illustrates the solute-solute interaction, and step 3 illustrates the final process, resulting in vertical phase segregation. The optical image shows the Marangoni effect.

very slow, delaying saturation of the solution. The TP molecules do not form large aggregates on the surface when trichlorobenzene is used and mostly remain in the P3HT matrix. This characteristic can be better observed in Fig. 6 (at magnification of $50 \mathrm{k} \times$ ), which shows good distribution of the two components and formation of continuous relief in the upper surface, which is percolated along the sample. Raised regions and valleys form the topography of the surface. The importance of this fact should be emphasized: a semiconductor layer with high mobility is created on the upper surface, and this may be advantageous for applications in transistors with top-gate architecture. The width of the raised regions seen in the image is in the order of $100 \mathrm{~nm}$. It is therefore worth mentioning that the raised relief is not formed exclusively by $\mathrm{TP}$ molecules.

The UV-Vis absorption spectra of spin-coated films of neat P3HT (in chloroform) and P3HT:TP blends (in chloroform, toluene, or trichlorobenzene) are shown in Fig. 7. The absorption values in each spectrum were divided by the maximum value, because we are only interested in comparing the shape of the curves (normalized by the peak value). Neat P3HT film exhibited one very intense peak at $512 \mathrm{~nm}$ and two other peaks at $550 \mathrm{~nm}$ and $598 \mathrm{~nm}$, which are attributed to vibronic transitions $\mathrm{A}_{0-2}$, $\mathrm{A}_{0-1}$, and $\mathrm{A}_{0-0}$ (where the subscripts denote the vibrational quanta coupled to electronic transitions), respectively. ${ }^{30,31}$ The two higher-energy absorption peaks, at $512 \mathrm{~nm}$ and $550 \mathrm{~nm}$, come from an intrachain exciton, ${ }^{32}$ while the lowest one, at $598 \mathrm{~nm}$, is due to an interchain exciton, resulting from the $\pi-\pi$ stacking interaction between P3HT chains. ${ }^{33,34}$ The UV-Vis spectra of the P3HT:TP blend films (obtained using chloroform, toluene, and trichlorobenzene) show red-shifted peaks compared with that for neat P3HT film (Fig. 7). As higher degrees of molecular order lead to longer wavelength shifts, ${ }^{35,36}$ it can be assumed that the presence of TP increases the molecular order of the films. In addition, the UV-Vis absorption peak at $\sim 600 \mathrm{~nm}$ (Fig. 7) of P3HT:TP film obtained in trichlorobenzene was noticeably stronger than those presented by the P3HT film and P3HT:TP blend films (obtained in chloroform and toluene). According to Lin et al. ${ }^{37}$ and Tsoi et al., ${ }^{38}$ the presence of the peak at $\sim 600 \mathrm{~nm}$ suggests strong $\pi-\pi$ interaction between P3HT chains and is one more indication of the ordering of P3HT molecules. The strongest peak at $\sim 600 \mathrm{~nm}$ observed for the P3HT:TP blend film obtained in trichlorobenzene indicates the highest degree of molecular order for this film, in agreement with the morphological features observed in the SEM images (Fig. 5). It is also important to point out that the ordering of molecules in semiconducting polymeric materials has significant effects on their optoelectronic properties; For instance, a high degree of molecular order can increase the charge carrier mobility when compared with the disordered form. ${ }^{25,39}$

The UV-Vis spectra of the P3HT:TP films (obtained in chloroform, toluene, and trichlorobenzene) 

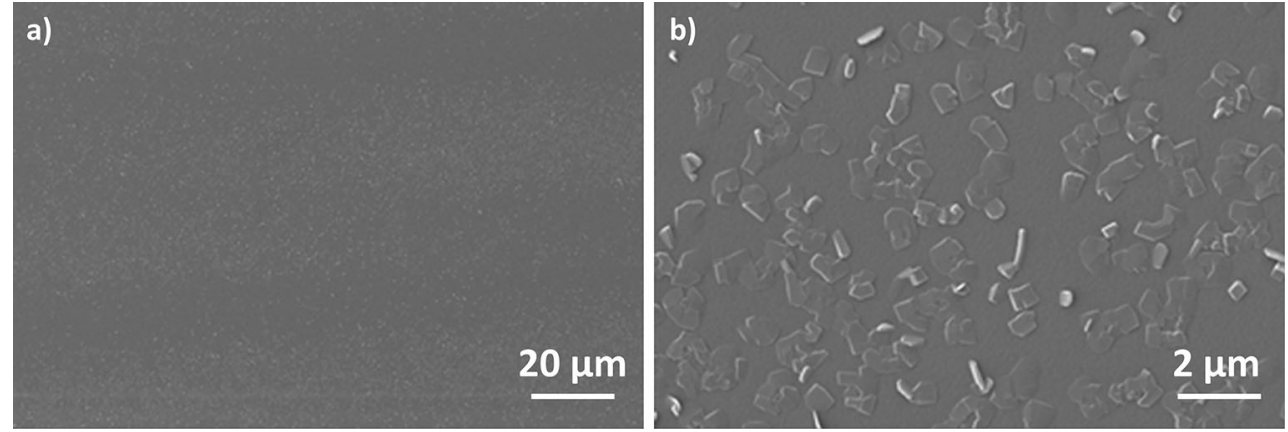

Fig. 4. SEM images of P3HT:TP blend film prepared with toluene at magnification of (a) $\times 1000$ and (b) $\times 10,000$.
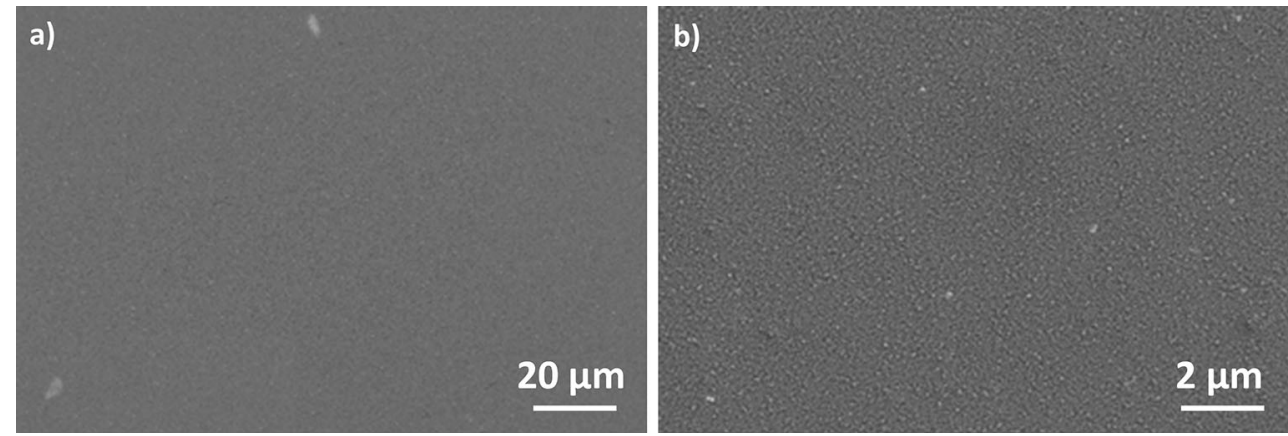

Fig. 5. SEM images of P3HT:TP blend films prepared using trichlorobenzene at magnification of (a) $\times 1000$ and (b) $\times 10,000$. The films are more homogeneous, and the segregation of TP is less intense.

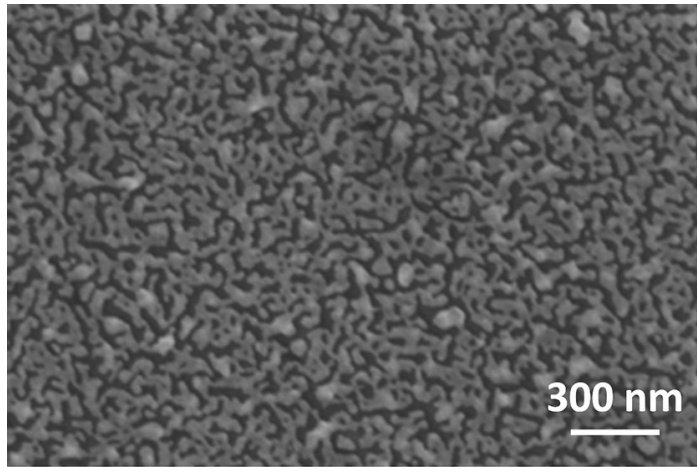

Fig. 6. SEM image of P3HT:TP blend film prepared using trichlorobenzene at magnification of $\times 50,000$.

exhibit two other peaks at $447 \mathrm{~nm}$ and $\sim 670 \mathrm{~nm}$, which can be assigned to $\mathrm{S}_{0} \rightarrow \mathrm{S}_{2}$ and $\mathrm{S}_{0} \rightarrow \mathrm{S}_{1}$ transitions, respectively, of the TP molecule. ${ }^{40}$ For the P3HT:TP blend films obtained in toluene and trichlorobenzene, the last absorption peak showed a red-shift compared with the same peak for the P3HT:TP film obtained in chloroform, indicating a narrower highest occupied molecular orbital (HOMO)-lowest unoccupied molecular orbital (LUMO) gap for both P3HT:TP films (obtained in toluene and trichlorobenzene). ${ }^{41}$

PL spectra of the neat P3HT film (in chloroform) and P3HT:TP blend films for the three different solvents are presented in Fig. 8. The PL spectrum for the neat P3HT film exhibits two peaks at $675 \mathrm{~nm}$

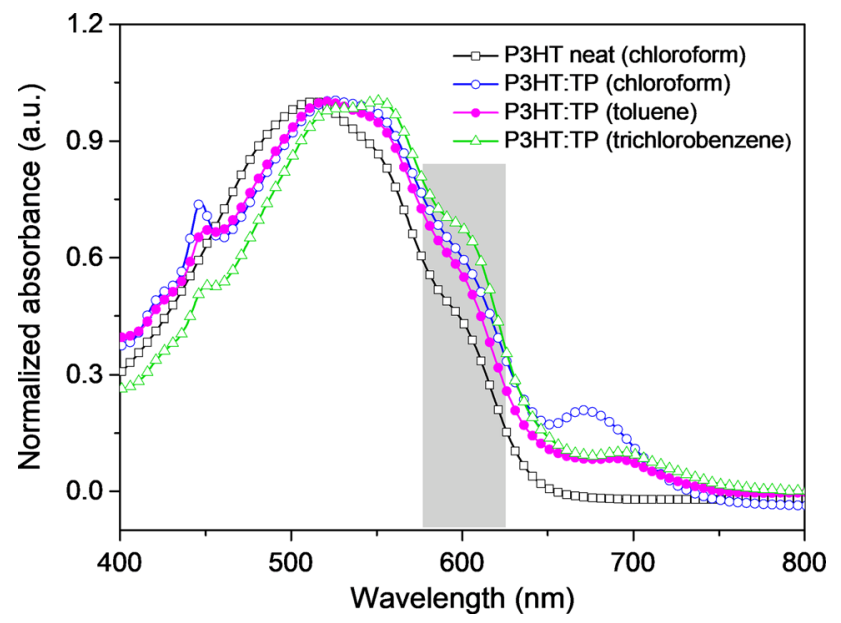

Fig. 7. UV-Vis absorption spectra of spin-coated films of neat $\mathrm{P} 3 \mathrm{HT}$ (in chloroform) and P3HT:TP blend films prepared in chloroform, toluene, or trichlorobenzene, deposited onto glass. The gray stripe highlights the peak at $\sim 600 \mathrm{~nm}$; each spectrum is normalized by its maximum absorption.

and $712 \mathrm{~nm}$, assigned to purely electronic transition and vibronic transition in the first vibrational state, respectively. ${ }^{42}$ When blending $\mathrm{P} 3 \mathrm{HT}$ with $\mathrm{TP}$ (in chloroform, trichlorobenzene, and toluene), quenching of the PL intensity can be observed. According to Korovyanko et al., ${ }^{43}$ such PL quenching in P3HT thin film suggests a more ordered phase of the molecules. Xie et al. ${ }^{44}$ noted the same behavior in 


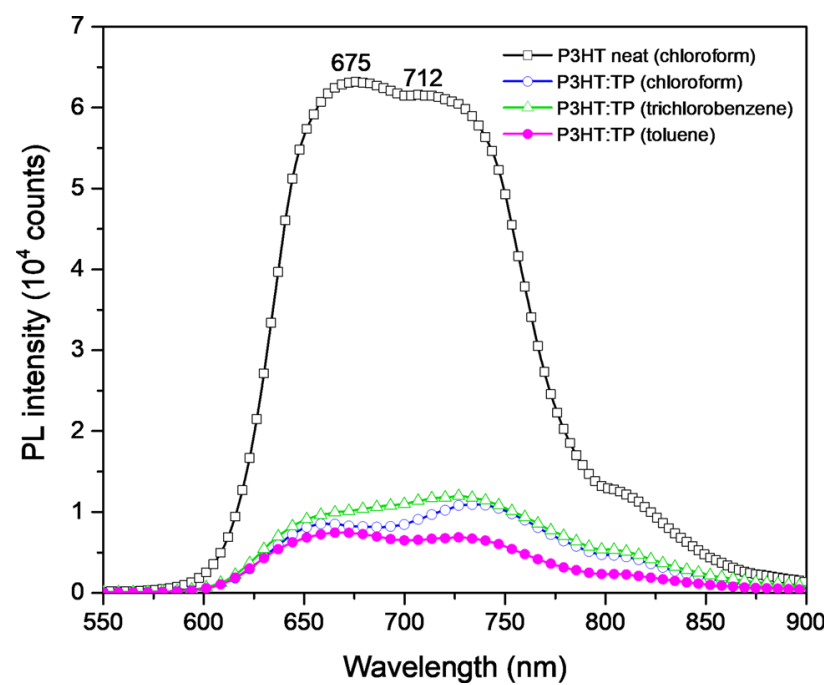

Fig. 8. Photoluminescence $(\mathrm{PL})$ spectra of spin-coated films of neat P3HT (in chloroform) and P3HT:TP blend films obtained in chloroform, toluene, and trichlorobenzene. All emission PL spectra were obtained at excitation wavelength of $510 \mathrm{~nm}$.

P3HT:phenyl-C61-butyric acid methyl ester (PCBM) blends. These results are explained in their work by suggesting that traps are created in the P3HT:PCBM film due to energy-level differences, leading to phase domains uniformly distributed throughout the bulk. The ordering of these phase domains plays an important role in heterojunction solar cells; For instance, in a photoactive layer, the carrier acceptor and donor formed by phase domains on nanometric scale uniformly distributed throughout the bulk improves the charge-transfer performance. Thus, the PL quenching of the P3HT:TP blend film obtained in trichlorobenzene, in association with the UV-Vis (highest degree of molecular ordering, Fig. 7) and morphology (more homogeneous distribution of molecules and less segregation, Fig. 5) results, indicates that this film has potential for use in heterojunction solar cell applications.

The PL spectra of neat P3HT film and P3HT:TP blend films in chloroform, trichlorobenzene, and toluene, deposited onto different interfaces (glass, $\mathrm{Al}_{2} \mathrm{O}_{3}$, and $\mathrm{Al}$ ) of the transistor, are shown in Fig. 9. The inset in Fig. 9 presents the three different interfaces of the transistor where the PL spectra were obtained. The PL intensity of the P3HT:TP blend films deposited onto $\mathrm{Al}_{2} \mathrm{O}_{3}$ and $\mathrm{Al}$ interfaces are higher than when deposited onto the glass interface. The reflection of light by the Al layer excites the material twice (going and returning), increasing the PL intensity. When varying the solvent and the interface (glass, $\mathrm{Al}_{2} \mathrm{O}_{3}$, and $\mathrm{Al}$ ), the PL spectral profile of the P3HT and P3HT:TP blend films did not change, remaining similar to each other. The exception was the P3HT:TP blend film in trichlorobenzene, for which inversion of the emission peaks was observed, as well as shifts to

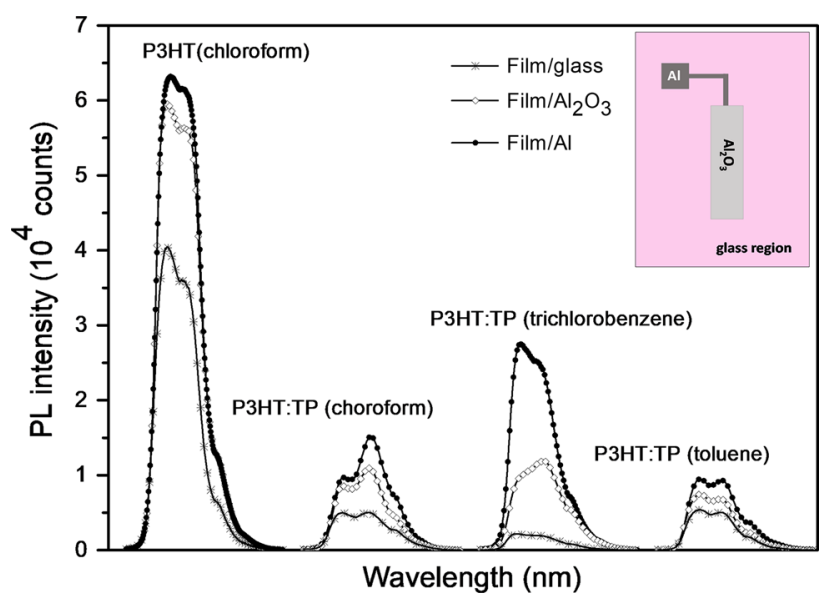

Fig. 9. Photoluminescence (PL) spectra of spin-coated films of neat P3HT (in chloroform) and P3HT:TP blend films obtained in chloroform, toluene, and trichlorobenzene, at different interfaces of the transistor: glass, aluminum oxide $\left(\mathrm{Al}_{2} \mathrm{O}_{3}\right)$, and aluminum (Al). All the emission PL spectra were obtained at excitation wavelength of $510 \mathrm{~nm}$.

longer wavelengths for the $\mathrm{Al}_{2} \mathrm{O}_{3}$ interface and shorter wavelengths for the $\mathrm{Al}$ interface (Fig. 9). In this case, the crystallization kinetics of the trichlorobenzene solution, associated with the energy and morphology of the different surfaces, can induce different lamellar arrangements of the molecules, which is reflected in the photoluminescence spectra.

The PL decay times $(\tau)$ of neat P3HT film and P3HT:TP blend films obtained in the three different solvents deposited on $\mathrm{Al}_{2} \mathrm{O}_{3}$ are presented in Table $\mathrm{I}$. Fitting was performed to one decay component for each emission wavelength, at $650 \mathrm{~nm}\left(\tau_{1}\right)$ and at $730 \mathrm{~nm}\left(\tau_{2}\right)$, which are closer to the PL emission of P3HT:TP films than to the PL emission of neat P3HT film.

The first observation that can be made based on these results is the short PL decay times of the P3HT:TP films (obtained in chloroform and toluene) compared with the neat P3HT film. The $\tau_{1}$ and $\tau_{2}$ processes of the P3HT:TP films $\left(\tau_{1}=180 \mathrm{ps}\right.$ and $\tau_{2}=220 \mathrm{ps}$ in chloroform and $\tau_{1}=170 \mathrm{ps}$ and $\tau_{2}=200 \mathrm{ps}$ in toluene) were much faster than normal relaxed singlet exciton recombination, which occurs in isolated P3HT chains and has a characteristic time scale of $\sim 600 \mathrm{ps},{ }^{45,46}$ as observed for the neat P3HT film $\left(\tau_{1}=460 \mathrm{ps}\right.$ and $\tau_{2}=500 \mathrm{ps}$ ). Considering the hypothesis suggested by Labastide et al., ${ }^{47}$ this short-time decay component derives from biexciton recombination, a cooperative effect between excitons on closely spaced adjacent chains in which recombination of one exciton enhances the probability of recombination with the adjacent exciton. The PL decay times found for the P3HT:TP film obtained in trichlorobenzene ( $\tau_{1}=1950 \mathrm{ps}$ and $\tau_{2}=1840 \mathrm{ps}$ ) were the longest, and can be associated with P3HT aggregates. ${ }^{48,49}$ In aggregated $\mathrm{P} 3 \mathrm{HT}$, charge separation followed by 
Table I. Decay times (1/e) of photoluminescence $(\tau)$ for P3HT:TP blend films obtained in chloroform, toluene, and trichlorobenzene, at $\mathrm{Al}_{2} \mathrm{O}_{3}$ interface

\begin{tabular}{|c|c|c|c|c|}
\hline & P3HT & P3HT:TP (Chloroform) & P3HT:TP (Toluene) & P3HT:TP (Trichlorobenzene) \\
\hline$\tau_{1}($ emission at $650 \mathrm{~nm})$ & $460 \mathrm{ps}$ & $180 \mathrm{ps}$ & $170 \mathrm{ps}$ & $1950 \mathrm{ps}$ \\
\hline$\tau_{2}($ emission at $730 \mathrm{~nm})$ & $500 \mathrm{ps}$ & $220 \mathrm{ps}$ & $200 \mathrm{ps}$ & $1840 \mathrm{ps}$ \\
\hline
\end{tabular}
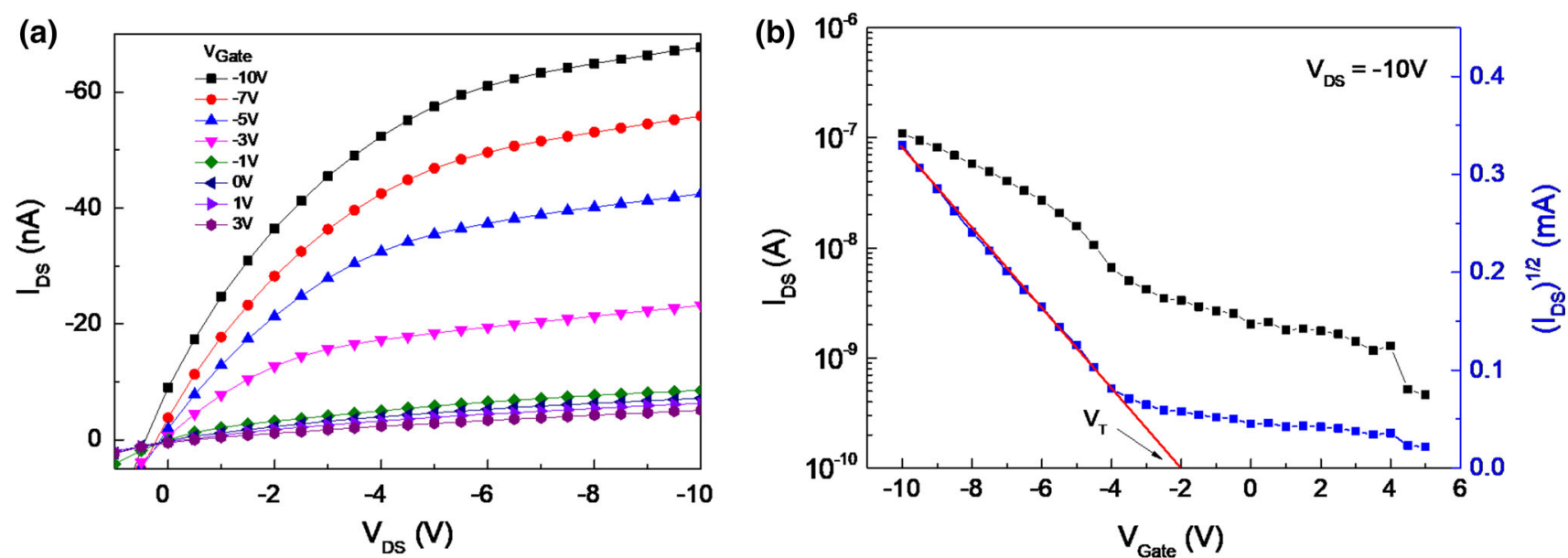

Fig. 10. Output and transfer curves of transistor using P3HT:TP prepared with chloroform: (a) output curve $I_{\mathrm{DS}}-V_{\mathrm{DS}}$ for various values of $V_{\mathrm{G}}$ and (b) transfer curve $I_{\mathrm{DS}}-V_{\mathrm{G}}$ for $V_{\mathrm{DS}}=-10 \mathrm{~V}$ (saturation regime). Mobility is $0.7 \times 10^{-3} \mathrm{~cm}^{2} \mathrm{~V}^{-1} \mathrm{~s}^{-1}$, and threshold voltage $\left(V_{\mathrm{T}}\right)$ is $\sim-2.0 \mathrm{~V}$.

(a)

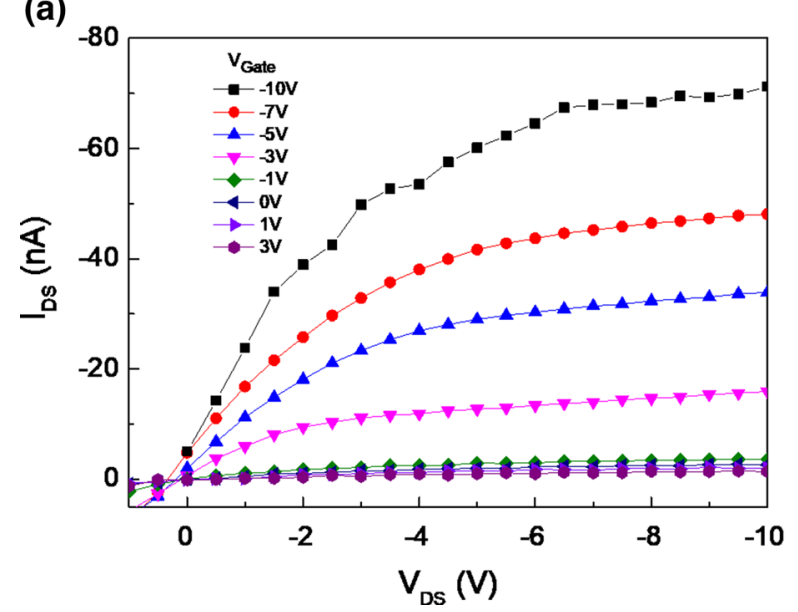

(b)

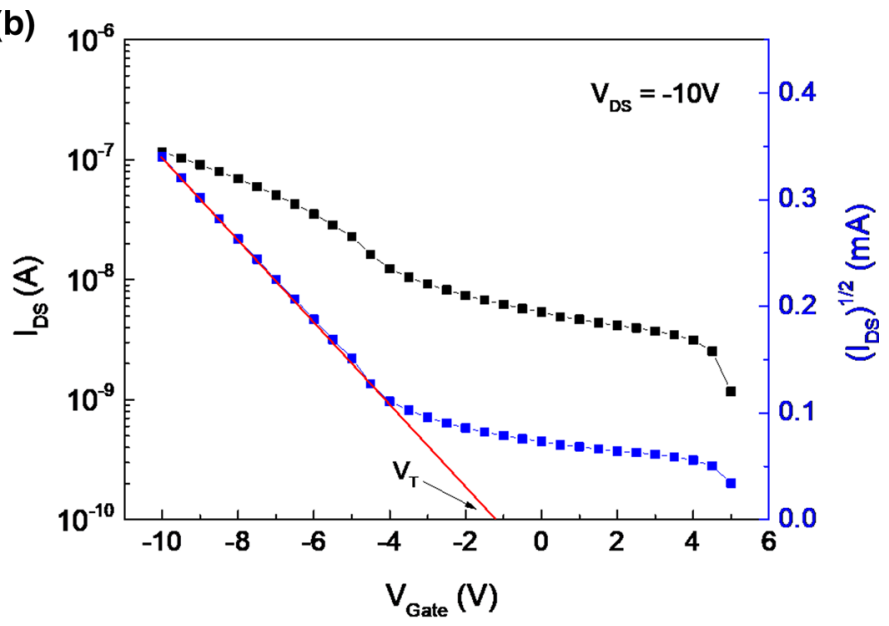

Fig. 11. Output and transfer curves of transistor using P3HT:TP prepared with toluene: (a) output curve $I_{\mathrm{DS}}-V_{\mathrm{DS}}$ for various values of $V_{\mathrm{G}}$ and (b) transfer curve $I_{\mathrm{DS}}-V_{\mathrm{G}}$ for $V_{\mathrm{DS}}=-10 \mathrm{~V}$ (saturation regime). Mobility is $1.0 \times 10^{-3} \mathrm{~cm}^{2} \mathrm{~V}^{-1} \mathrm{~s}^{-1}$, and threshold voltage $\left(V_{\mathrm{T}}\right)$ is $-1.4 \mathrm{~V}$.

carrier diffusion and recombination via tunneling is associated with long-time photoluminescence decay. ${ }^{50,51}$

The output and transfer curves for the transistors formed using P3HT:TP blend films prepared with chloroform, toluene, and trichlorobenzene are shown in Figs. 10, 11, and 12, respectively. The threshold voltage is $\sim-2.0 \mathrm{~V},-1.4 \mathrm{~V}$, and $-1.3 \mathrm{~V}$, and the mobility calculated from the transfer curves (Figs. 10b, 11b, and 12b) is $0.7 \times 10^{-3} \mathrm{~cm}^{2} \mathrm{~V}^{-1} \mathrm{~s}^{-1}, \quad 1.0 \times 10^{-3} \mathrm{~cm}^{2} \mathrm{~V}^{-1} \mathrm{~s}^{-1}$, and $5.0 \times 10^{-3} \mathrm{~cm}^{2} \mathrm{~V}^{-1} \mathrm{~s}^{-1}$ for the blend films obtained using chloroform, toluene, and trichlorobenzene, respectively. The output current was three times $(3 \times)$ larger for the transistor prepared using trichlorobenzene compared with the other solvents. The improved mobility is due to better P3HT crystalline lamella organization, an 
(a)

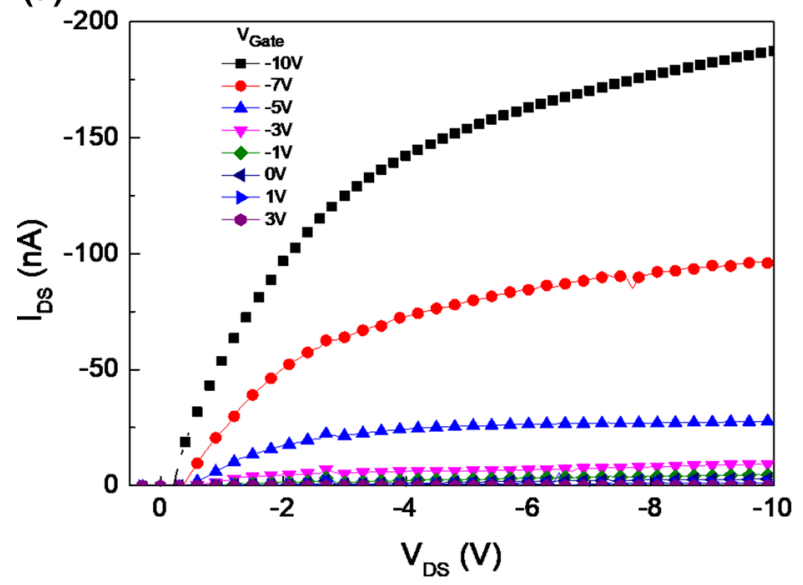

(b)

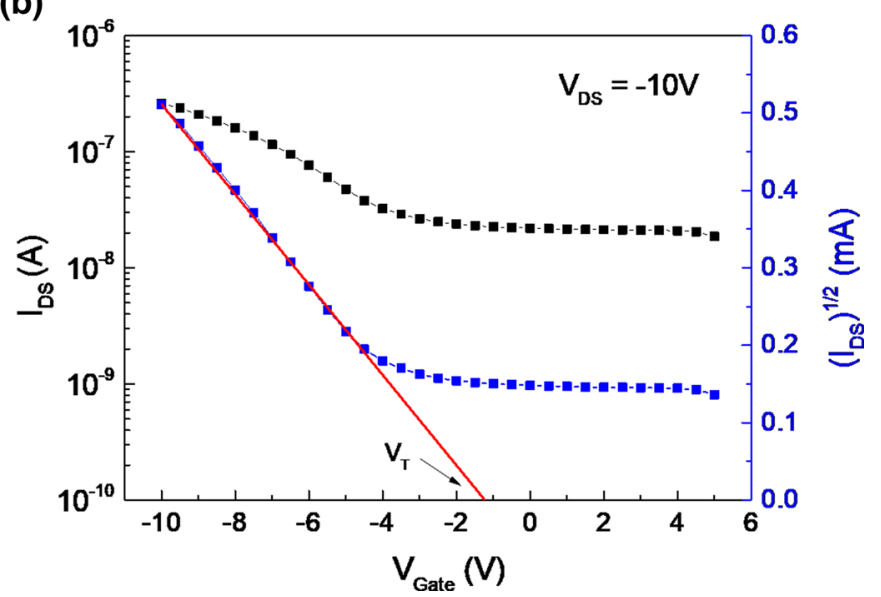

Fig. 12. Output and transfer curves of transistor using P3HT:TP prepared with trichlorobenzene: (a) output curve $I_{\mathrm{DS}}-V_{\mathrm{DS}}$ for various values of $V_{\mathrm{G}}$ and (b) transfer curve $I_{\mathrm{DS}}-V_{\mathrm{G}}$ for $V_{\mathrm{DS}}=-10 \mathrm{~V}$ (saturation regime). Mobility is $5.0 \times 10^{-3} \mathrm{~cm}^{2} \mathrm{~V}^{-1} \mathrm{~s}^{-1}$, and threshold voltage $\left(V_{\mathrm{T}}\right)$ is $-1.3 \mathrm{~V}$.

effect observed for less volatile solvents, as discussed above.

These results are still far from what would be expected if the TP mobility prevailed. This occurred because the mobility was extracted from one device with bottom gate and top contact, where the driving current is localized in an accumulation layer in the interface with the dielectric while the TP molecules are concentrated on the upper surface. For this reason, it can be inferred that the mobility would be better in a top-gate configuration, in which conduction is localized in a region where the TP molecules are concentrated. In summary, it can be stated that solvent volatility and the characteristics of the substrate surface are of great importance in the blend preparation, drastically influencing its morphology.

\section{CONCLUSIONS}

We demonstrated that films of P3HT:TP blends prepared using chloroform, toluene, and trichlorobenzene showed optical properties that depended on the solvent applied. For each of the three solvents, we observed that presence of TP increased the molecular order of the films compared with neat P3HT. The difference between the HOMO and LUMO energy level confined the carriers, delaying recombination of excitons when the sample was illuminated. Thus, quenching of PL and increased carrier lifetime were observed when TP was added to P3HT. It should be emphasized that, in terms of PL quenching and dissociation time and phase segregation of excitons, the P3HT:TP blend is similar to the P3HT:PCBM blend widely used in heterojunction photovoltaic devices. Also, PL measurements showed that the exciton dissociation depends on the characteristics of the surface of the film on which it is deposited. The best output current performance was obtained using P3HT:TP prepared with trichlorobenzene, and this improvement is mainly attributed to the better organization that occurs in P3HT domains. In summary, the solvent has crucial effects on the properties of P3HT:TP films.

\section{ACKNOWLEDGEMENTS}

The authors thank the Fundação de Amparo à Pesquisa do Estado de São Paulo (FAPESP), Programa de Pós-Graduação em Ciência e Tecnologia de Materiais (POSMAT), Coordenação de Aperfeiçoamento do Ensino Superior (CAPES), Fundação Araucária do Paraná, Conselho Nacional de Desenvolvimento Científico e Tecnológico (CNPq), and Laboratório ESPEC- Multiusuário-UEL for technical and financial support.

\section{REFERENCES}

1. K. Wang, R. Chen, F. Zhuang, C. Chen, S. Su, and Y. Xiang, Thin Solid Films 584, 359 (2015).

2. B. Kang, W.H. Lee, and K. Cho, ACS Appl. Mater. Interfaces 5, 2302 (2013).

3. G. Gelinck, P. Heremans, K. Nomoto, and T.D. Anthopoulos, Adv. Mater. 22, 3778 (2010).

4. H. Sirringhaus, Adv. Mater. 17, 2411 (2005).

5. Y.Y. Lin, D.J. Gundlach, S.F. Nelson, and T.N. Jackson, IEEE Trans. Electr. Dev. 44, 1325 (1997).

6. Y.Y. Lin, D.J. Gundlach, S.F. Nelson, and T.N. Jackson, IEEE Trans. Electr. Dev. 18, 606 (1997).

7. T. Minakata and Y. Natsume, Synth. Met. 153, 1 (2005).

8. J. Smith, R. Hamilton, I. McCulloch, N.S. Stutzmann, M. Heeney, D.D.C. Bradley, and T.D. Anthopoulos, J. Mater. Chem. 20, 2562 (2010).

9. S. Subramanian, S.K. Park, S.R. Parkin, V. Podzorov, T.N. Jackson, and J.E. Anthony, J. Am. Chem. Soc. 130, 2706 (2008).

10. M.W. Lee, G.S. Ryu, Y.U. Lee, C. Pearson, M.C. Petty, and C.K. Song, Microelectron. Eng. 94, 1 (2012).

11. M.B. Madec, P.J. Smith, A. Malandraki, N. Wang, J.G. Korvink, and S.G. Yeates, J. Mater. Chem. 20, 9155 (2010).

12. H.B. Akkerman, H. Li, and Z. Bao, Org. Electron. 13, 2056 (2012).

13. C.M. Keum, J.H. Kwon, S.D. Lee, and J.H. Bae, Sol. Stat. Electron. 89, 189 (2013).

14. S.Y. Cho, J.M. Ko, J.Y. Jung, J.Y. Lee, D.H. Choi, and C. Lee, Org. Electron. 13, 1329 (2012). 
tacene Blends

15. M.S. Ozório, G.L. Nogueira, R.M. Morais, C.S. Martin, C.J.L. Constantino, and N. Alves, Thin Solid Films 608, 97 (2016).

16. D.M. Russell, C.J. Newsome, S.P. Li, T. Kugler, and M. Ishida, Appl. Phys. Lett. 87, 222109 (2005).

17. H. Zhao, Z. Wang, G. Dong, and L. Duan, Phys. Chem. Chem. Phys. 17, 6274 (2015).

18. J.H. Park, H. Lim, H. Cheong, K.M. Lee, H.C. Sohn, G. Lee, and S. Im, Org. Electron. 13, 1250 (2012).

19. D.K. Hwang, C.F. Hernandez, J.D. Berrigan, Y. Fang, J. Kim, W.J. Potscavage, H. Cheun, K.H. Sandhage, and B. Kippelen, J. Mater. Chem. 22, 5531 (2012)

20. H. Minemawari, T. Yamada, H. Matsui, J. Tsutsumi, S. Haas, R. Chiba, R. Kumai, and T. Hasegawa, Nature 475, 364 (2011).

21. Y. Diao, B.C.K. Tee, G. Giri, J. Xu, D.H. Kim, H.A. Becerril, R.M. Stoltenberg, T.H. Lee, G. Xue, S.C.B. Mannsfeld, and Z. Bao, Nat. Mater. 12, 665 (2013).

22. K.W. Chou, H.U. Khan, M.R. Niazi, B. Yan, R. Li, M.M. Payne, J.E. Anthony, D.M. Smilgies, and A. Amassian, J. Mater. Chem. C 2, 5681 (2014).

23. G.H. Fredrickson, A.J. Liu, and F.S. Bates, Macromolecules 27, 2503 (1994).

24. C.M. Bjorstrom, K.O. Magnusson, and E. Moons, Synth. Met. 152, 109 (2005)

25. C. Ton-That, A.G. Shard, D.O.H. Teare, and R.H. Bradley, Polymer 42, 1121 (2001)

26. S.I. Jun and H.S. Lee, Curr. Appl. Phys. 12, 467 (2012)

27. D.P. Birnie, Langmuir 29, 9072 (2013).

28. J.M. Patete, X. Peng, J.M. Serafin, and S.S. Wong, Langmuir 27, 5792 (2011)

29. S.B. Jung, T.J. Ha, and H.H. Park, J. Appl. Phys. 101, 024109 (2007)

30. A.R. Aiyar, J.I. Hong, R. Nambiar, D.M. Collard, and E. Reichmanis, Adv. Funct. Mater. 21, 2652 (2011).

31. G. Nagarjuna, M. Baghgar, J.A. Labastide, D.D. Algaier, M.D. Barnes, and D. Venkataraman, ACS Nano 6, 10750 (2012).

32. S. Falke, P. Eravuchira, A. Materny, and C. Lienau, J. Raman Spectrosc. 42, 1897 (2011).

33. P.J. Brown, D.S. Thomas, A. Kohler, J.S. Wilson, J.S. Kim, C.M. Ramsdale, H. Sirringhaus, and R.H. Friend, Phys. Rev. B 67, 060101(R) (2003).

34. J. Piris, T.E. Dykstra, A.A. Bakulin, P.H.M. van Loosdrecht, W. Knulst, M.T. Trinh, J.M. Schins, and L.D.A. Siebbeles, J. Phys. Chem. C 113, 14500 (2009).
35. H. Sirringhaus, P.J. Brown, R.H. Friend, M.M. Nielsen, K. Bechgaard, B.M.W. Langeveld-Voss, A.J.H. Spiering, R.A.J. Janssen, E.W. Meijer, P. Herwig, and D.M. Leeuw, Nature 401, 685 (1999).

36. C.J. Lin, C.L. Liu, and W.C. Chen, J. Mater. Chem. C 3, 4290 (2015)

37. Y. Lin, J.A. Lim, Q. Wei, S.C.B. Mannsfeld, A.L. Briseno, and J.J. Watkins, Chem. Mater. 24, 622 (2012).

38. W.C. Tsoi, D.T. James, J.S. Kim, P.G. Nicholson, C.E. Murphy, D.D.C. Bradley, J. Nelson, and J.S. Kim, J. Am. Chem. Soc. 133, 9834 (2011).

39. S.S. Pandey, W. Takashima, S. Nagamatsu, T. Endo, M. Rikukawa, and K. Kaneto, J. Appl. Phys. 39, 94 (2000).

40. M.J.Y. Tayebjee, K.N. Schwarz, R.W. MacQueen, M. Dvorák, A.W.C. Lam, K.P. Ghiggino, D.R. McCamey, T.W. Schmidt, and G.J. Conibeer, J. Phys. Chem. C 120, 157 (2016).

41. Y.D. Zhang, Y. Wu, Y. Xu, Q. Wang, K. Liu, J.W. Chen, J.J. Cao, C. Zhang, H. Fu, and H.L. Zhang, J. Am. Chem. Soc. 138, 6739 (2016).

42. W.C. Tsoi, S.J. Spencer, L. Yang, A.M. Ballantyne, P.G. Nicholson, A. Turnbull, A.G. Shard, C.E. Murphy, D.D.C. Bradley, J. Nelson, and J.S. Kim, Macromolecules 44, 2944 (2011).

43. O.J. Korovyanko, R. Österbacka, X.M. Jiang, Z.V. Vardeny, and R.A.J. Janssen, Phys. Rev. B 64, 235122 (2001).

44. Y. Xie, Y. Li, L. Xiao, Q. Qiao, R. Dhakal, Z. Zhang, Q. Gong, D. Galipeau, and X. Yan, J. Phys. Chem. C 114, 14590 (2010).

45. E. Busby, E.C. Carroll, E.M. Chinn, L. Chang, A.J. Moulé, and D.S. Larsen, J. Phys. Chem. Lett. 2, 2764 (2011).

46. N. Banerji, S. Cowan, E. Vauthey, and A.J. Heeger, J. Phys. Chem. C 115, 9726 (2011).

47. J.A. Labastide, M. Baghgar, A. McKenna, and M.D. Barnes, J. Phys. Chem. C 116, 23803 (2012).

48. O.G. Reid, J.A.N. Malik, G. Latini, S. Dayal, N. Kopidakis, C. Silva, N. Stingelin, and G. Rumbles, Polym. Sci. Part B Polym. Phys. 50, 27 (2011).

49. E. Busby, C.W. Rochester, A.J. Moulé, and D.S. Larsen, Chem. Phys. Lett. 513, 77 (2011).

50. G. Hukic-Markosian, T. Basel, S. Singh, Z.V. Vardeny, S. Li, and D. Laird, Appl. Phys. Lett. 100, 21 (2012).

51. F. Paquin, G. Latini, M. Sakowicz, P.L. Karsenti, L. Wang, D. Beljonne, N. Stingelin, and C. Silva, Phys. Rev. Lett. 106, 197401 (2011). 